\title{
Lower threshold for adenosine-induced chest pain in patients with angina and normal coronary angiograms
}

\author{
Bo Lagerqvist, Christer Sylvén, Anders Waldenström
}

\begin{abstract}
Objective-To investigate whether patients with angina-like chest pain and normal coronary angiograms are more sensitive to adenosine as an inducer of chest pain.
\end{abstract}

Design-Increasing doses of adenosine were given in a single blind study as intravenous bolus injections. Chest pain and the electrocardiographic findings were noted.

Patients-Eight patients with anginalike chest pain but no coronary stenoses (group A), nine patients with angina and coronary stenoses (group B), and 16 healthy volunteers (group C).

Results-In the absence of ischaemic signs on the electrocardiogram adenosine provoked angina-like pain in all patients in groups $A$ and $B$. The pain was located in the chest, and its quality and location were described as being no different from the patient's habitual angina. In group $C, 14$ of 16 subjects reported chest pain. The lowest dose resulting in chest pain was lower in group A $(0.9(0.6) \mathrm{mg})$ than in group $B$ $(3.1(1.5) \mathrm{mg})(\mathrm{p}<0.005)$ and in group $C$ $(6.2(3.7) \mathrm{mg})(\mathrm{p}<0.005)$. The maximum tolerable dose was lower in group $A(4 \cdot 7$ $(2 \cdot 1) \mathrm{mg})$ than in group $B(9.2(3.8) \mathrm{mg})$ $(p<0.05)$ and in group $C(12.0(4.1) \mathrm{mg})$ (p $<0.005)$.

Conclusions-Patients with anginalike chest pain and normal coronary angiograms have a low pain threshold and low tolerance to pain induced by adenosine.

\section{(Br Heart J 1992;68:282-5)}

Despite studies on many patients with anginalike pain and normal coronary angiograms, the mechanisms of the syndrome are unclear. ${ }^{1-4}$ The causes may be multifactorial and a decreased capacity to dilate the coronary arteries and to increase coronary blood flow in response to pharmacological provocation with dipyridamole or rapid atrial pacing has been suggested. ${ }^{56} \mathrm{~A}$ lower threshold and tolerance to both ischaemic pain and electrical skin stimulation on the forearm have been reported in women with syndrome $\mathrm{X}$.

The links between myocardial ischaemia and chest pains are not completely clear though adenosine was proposed by Sylven et al to be a metabolic messenger. ${ }^{89}$ Adenosine given intravenously or directly into a coronary artery induced angina-like pains without the electrocardiographic (ECG) signs of ischaemia both in patients with ischaemic heart disease in healthy volunteers. ${ }^{81011}$ Patients with predominantly silent ischaemia tolerate higher doses of adenosine than patients with predominantly painful ischaemia. ${ }^{12}$

When dipyridamole is given to patients with ischaemic heart disease for the study of thallium-201 scinitigraphy or echocardiography, chest pains are reported by up to $40 \%$ of the patients. When dipyridamole was given to patients with angina pectoris and normal coronary angiograms $68-95 \%$ of the patients reported chest pains. ${ }^{21314}$ Dipyridamole has several mechanisms of action and an important one is an increased extracellular concentration of adenosine caused by the inhibition of the cellular uptake of adenosine. ${ }^{15}$

Because this suggested a role for adenosine we studied whether patients with angina-like pains and angiographically normal coronary arteries have a lower tolerance to adenosine as a pain inducer.

\section{Patients and methods \\ PATIENTS}

Group A comprised eight patients (three male) with typical effort related angina but without any stenosis on the coronary angiograms. Their mean (SD) age was 56 (13) years and mean (SD) weight 68 (7) kg. All had localised perfusion defects on thallium-201 myocardial scintigraphy at exercise with reversibility at rest. All these perfusion defects had primarily been interpreted as being of the "ischaemic type". Five of the eight patients had horizontal or down sloping ST segment depression of at least $0.1 \mathrm{mV}$ and chest pains on an ergometer exercise stress test: the rest had only chest pain without any ST depression. All patients had previously been paced to pain (mean frequency 154 (22) beats/min) and three of the eight had signs of myocardial lactate production with a higher lactate concentration in coronary sinus blood than in arterial blood. Five of the patients were classified as functional group III and three as functional group II according to the New York Heart Association (NYHA) classification. No-one in group A had a previous history of myocardial infarction, hypertension, or diabetes. The results of left ventricular angiography and the echocardio- 
graphy were classified as normal in all patients in group A. None of the patients showed any signs of coronary spasm during hyperventilation or a non-invasive ergometrine (ergonovine) test. ${ }^{14} 16$

Group B comprised nine patients (all men) with angina and coronary stenosis, (at least $50 \%$ diameter reduction) on coronary angiography. Three of them had one vessel disease, one had one vessel disease and main stem stenosis, two had two vessel disease, and three had three vessel disease. A previous myocardial infarction had been clinically diagnosed in four of the patients. Four of them were treated for hypertension. All of the patients were classified as belonging to NYHA functional group III. Their mean age was 58 (6) years and mean weight was $78(8) \mathrm{kg}$.

Group $C$ was a control group of 16 healthy volunteers (six men) aged 43 (8) years and with a mean weight of 68 (11) kg. None of them had any history or symptoms suggesting heart disease.

All antianginal medication was stopped and the subjects were told to abstain from xanthine-containing food and drinks for at least 12 hours before the experiment. No other premedication was given except $3 \mathrm{~g}$ amoxycillin and $15 \mathrm{mg}$ oxazepam to those who were catheterised to measure coronary sinus blood flow at the same time.

The study was approved by the local ethics committee. The background and the procedure were thoroughly explained to the subjects before consent was obtained.

\section{PROCEDURE}

The sterile solution of adenosine $(5.3 \mathrm{mg} / \mathrm{ml}$, Janssen) was prepared by the hospital pharmacy. In a single blind manner adenosine or saline was injected rapidly as a bolus injection into an antebrachial vein. After each dose the vein was flushed with $5 \mathrm{ml}$ saline. The initial dose was $2.5 \mathrm{mg}$ adenosine. Based on the pain response the dose was increased or decreased in small steps in order to reach the "highest dose not giving pain" and the "lowest dose giving pain". The adenosine dose was changed in a single blind manner in irregular steps and adenosine was alternated with injections of saline. The dose was thereafter increased step by step until the subject refused a further increase, ST depression was seen on the electrocardiogram, or an atrioventricular block II-III occurred. This dose was defined as the "maximum dose". The dose intervals were lower for low doses and higher when higher doses were given. Doses of adenosine between 0.1 and $15 \mathrm{mg}$ were given. The next dose was given 3-5 minutes after the disappearance of pain or other symptoms caused by the previous dose.

At the onset of pain the patient raised his or her left hand, when the maximum pain began to subside the hand was lowered half way, and when the pains had disappeared the hand was lowered to the supine position. These time points were noted on the online recording of the electrocardiogram (V1-V6) $(25 \mathrm{~mm} / \mathrm{s})$. The magnitude of maximal pain was rated according to a category-ratio scale designed to quantify perceptual intensities, the Borg CR-10 scale. ${ }^{17}$ The patient was also asked to describe the location and the character of the pain, especially with respect to differences from and similarities to his/her experience of angina.

In five patients in group $A$ and five patients in group B a coronary sinus flow catheter (WiltonWebster, USA) was introduced via the right internal jugular vein into the coronary sinus under fluoroscopic control. The position was tested by injection of contrast medium. The coronary sinus blood flow was determined by the thermodilution technique. ${ }^{18}$

\section{STATISTICAL ANALYSIS}

Values are expressed as means (SD) unless otherwise stated. We used the Kruskal-Wallis test for analysis of variance, the MannWhitney $U$ test for intergroup differences between unpaired samples, and the Wilcoxon signed rank test to test for statistical heterogeneity between paired samples.

\section{Results}

In the absence of ischaemic electrocardiographic signs injection of adenosine into a peripheral vein induced pain in all patients in groups A and B. The pain was mainly located in the chest and was described as being the same as the patient's habitual angina in quality and location. In group $C$ intravenous injection of adenosine resulted in chest pain in 14 of 16 subjects. In two of the subjects the dose was not increased because an atrioventricular block occurred before any chest pain was noted.

Table 1 and fig 1 summarise the pain reactions to adenosine injection. The highest dose not giving pains, the lowest dose giving pains, the maximum dose of adenosine were lower in group $A$ than in group $B$ and in group $C$. These differences were all statistically significant $(p<0.05)$ and the differences in threshold remained when differences in body weight were accounted for. The pain appeared earlier $(p<0.005)$ and lasted longer $(p<0.001)$ after

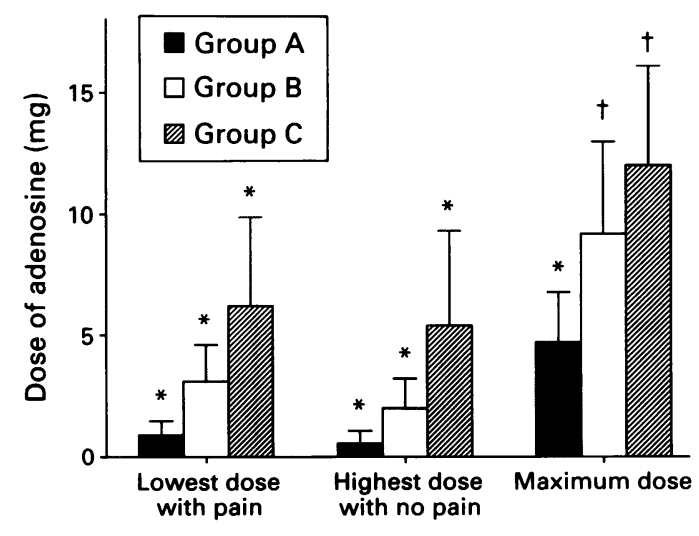

Figure 1 Lowest dose of adenosine provoking pain, highest dose not giving pain, and maximum dose when adenosine was injected intravenously in the different groups of patients. Analysis of the variance was by the groups of patients. Analysis of the variance was by
Kruskal-Wallis test and localisation of intergroup differences by the Mann-Whitney $U$ test.

$\star$ Different from the other two groups $(p<0.05)$; †different from group $A(p<0.05)$. 
Table 1 Highest dose of adenosine not giving pains, lowest dose giving pains, maximum dose, degree of pain according to Borg CR-10 scale at maximum dose of adenosine, time from injection to start of pain, and duration of pain when adenosine was injected intravenously into the different groups of patients

\begin{tabular}{|c|c|c|c|c|}
\hline & $\begin{array}{l}\text { Group } A \\
(n=8)\end{array}$ & $\begin{array}{l}\text { Group B } \\
(n=9)\end{array}$ & $\begin{array}{l}\text { Group C } \\
(n=16)\end{array}$ & $\begin{array}{l}\text { Analysis of } \\
\text { variance } \\
\text { p value }\end{array}$ \\
\hline $\begin{array}{l}\text { Highest dose not giving pains (mg) } \\
\text { Lowest dose giving pains (mg) } \\
\text { Maximum dose (mg) } \\
\text { Pain degree at maximum dose (Borg CR-10) } \\
\text { Time to pain at lowest dose giving pain (s) } \\
\text { Pain duration at lowest dose giving pain (s) } \\
\text { Time to pain at maximum dose giving pain (s) } \\
\text { Pain duration at maximum dose giving pain (s) }\end{array}$ & $\begin{array}{l}0 \cdot 6(0 \cdot 5)^{\star} \\
0 \cdot 9(0 \cdot 6)^{\star} \\
4 \cdot 7(2 \cdot 1)^{\star} \\
7 \cdot 4(1 \cdot 5) \\
20(5) \\
18(10) \\
18(4) \\
31(10)\end{array}$ & $\begin{array}{l}2 \cdot 0(1 \cdot 2)^{\star} \\
3 \cdot 1(1 \cdot 5)^{\star} \\
9 \cdot 2(3 \cdot 8) \dagger \\
6 \cdot 2(1 \cdot 9) \\
22(5) \\
18(9) \\
18(5) \\
30(26)\end{array}$ & $\begin{array}{l}5 \cdot 4(3 \cdot 9)^{\star} \\
6 \cdot 2(3 \cdot 7)^{\star} \\
12 \cdot 0(4 \cdot 1) \dagger \\
4 \cdot 5(2 \cdot 3) \dagger \\
20(7) \\
19(16) \\
16(4) \\
29(15)\end{array}$ & $\begin{array}{l}<0.001 \\
<0.001 \\
<0.001 \\
<0.01 \\
>0.2 \\
>0.2 \\
>0.2 \\
>0.2\end{array}$ \\
\hline
\end{tabular}

Analysis of the variance by Kruskal-Wallis test and localisation of intergroup differences by Mann-Whitney U test.

*Different from the other two groups, $\mathrm{p}<0.05$; †different from group $\mathrm{A}, \mathrm{p}<0.05$

the maximum dose than after the lowest dose of adenosine. The degree of pain, according to the Borg CR-10 scale, was lower in group $C$ than in group A $(p<0.05)$. Figure 2 highlights the relation between the maximum dose of adenosine given and the degree of the reported pain.

Short periods of atrioventricular block II and III developed in 15 subjects (one in group $A$, three in group $B$, and 11 in group $C$ ) and a short sinus arrest/sinoatrial block was seen in one of the subjects (group B) after adenosine injection. The longest duration of block was $5 \mathrm{~s}$. The mean lowest dose of adenosine resulting in block was $10.0(4.3) \mathrm{mg}$. The mean time from the start of the injection to the beginning of the block was 15 (4) s, and this was not statistically different from the time of injection to onset of pain (16 (4) s) in these subjects. The uneven distribution of the appearance of atrioventricular blocks could not be taken as an indication of different electrophysiological response to adenosine in the three groups because the maximum doses differed between the groups.

Table 2 shows the effect of adenosine on coronary sinus blood flow. There was no statistically significant difference between groups $\mathrm{A}$ and $B$ in terms of the beginning of the increase in coronary sinus blood flow or in the time from injection to flow increase or from injection to maximum flow. Nor was there any difference in

Figure 2 Relation between the maximal bolus dose of adenosine given intravenously and the degree of pain provoked according to the Borg $C R-10$ scale in groups $A$, $B$, and $C$.

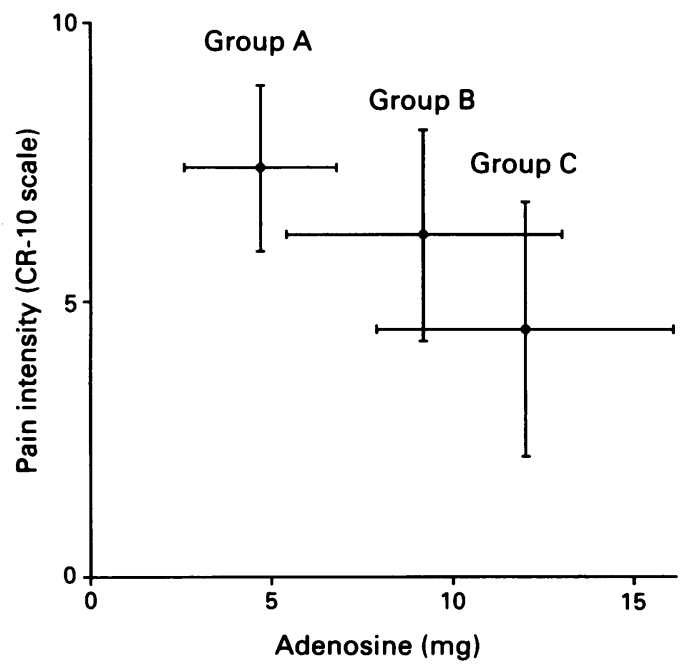

the increase of flow between the lowest dose giving pain and the maximum dose.

When the results for all the subjects were analysed together we found that the lowest dose giving pain resulted in a coronary sinus blood flow increase that came earlier $(15$ (4) s) than the pain (21 (4) s, p $<0.01$ ). This also occurred when the maximum dose of adenosine was injected (15 (3) s and 18 (4) s, respectively, $\mathrm{p}<0.01)$.

Injection of saline did not result in any pain or increase in coronary sinus blood flow or lead to atrioventricular block in any of the patients.

\section{Discussion}

Both in the group with angina-like pains and normal coronary angiograms (group A) and in the group with ischaemic heart disease (group B) the pains induced by adenosine were described as being no different from the usual exercise induced chest pain. Group A was more sensitive to adenosine. This could be an expression of a generally higher sensitivity to pain of different causes or specifically to pain evoked by adenosine. Turiel et al found a lower threshold and a lower tolerance both to ischaemic forearm pain and to electrical skin stimulation, but not to cold in women with syndrome $\mathrm{X}$ than in those with stable angina and coronary stenoses. ${ }^{7}$ Another study of a group of patients with normal coronary angiograms found that despite a higher pain sensitivity in the right side of the heart to catheter manipulations the threshold for cutaneous pain stimulation by heat was higher than in a group of patients with ischaemic heart disease. ${ }^{19}$

In the myocardium adenosine is produced under normal conditions and acts as a local vasodilator..$^{20}$ During ischaemia its production is greatly enhanced and it is released in large quantities into the coronary circulation. ${ }^{2122}$ The difference between normal physiology and ischaemia is not qualitative but quantitativewith increasing energy expenditure increasing amounts of adenosine are released. ${ }^{23}$ Our study implies an increased sensitivity also to endogenously produced adenosine. This could explain why patients with angina without coronary stenoses report pain in the absence of signs of ischaemia such as pathologically increased exertional diastolic pulmonary artery 
Table 2 Effects of adenosine on coronary sinus blood flow (CSBF) in groups $A$ and $B$

\begin{tabular}{lcc}
\hline & $\begin{array}{c}\text { Group } A \\
(n=5)\end{array}$ & $\begin{array}{c}\text { Group } B \\
(n=5)\end{array}$ \\
\hline Increase in CSBF, as \% of baseline flow, maximum dose & $202(84)$ & $211(94)$ \\
Time to CSBF increase at lowest dose giving pain (s) & $14(2)$ & $16(5)$ \\
Time to CSBF maximum at lowest dose giving pain (s) & $22(2)$ & $27(7)$ \\
Time to CSBF increase at maximum dose of adenosine (s) & $14(1)$ & $15(5)$ \\
Time to CSBF maximum at maximum dose of adenosine (s) & $23(3)$ & $25(5)$ \\
\hline
\end{tabular}

pressure $^{24}$ or such as hypokinesia during the dipyridamole echocardiography test. ${ }^{13}$ It is not known whether or not myocardial ischaemia is the main cause of chest pains in this group of patients. The exercise induced chest pains in these patients are not necessarily caused by ischaemia. It is possible that this group of patients has pain at adenosine concentrations that are lower than those caused by ischaemia, or that they have raised resting concentrations of adenosine that are nearer the threshold concentration for pain.

This study does not exclude an extracardiac origin for the adenosine induced pain, but a cardiac origin is the most likely. In patients with ischaemic heart disease both intravenous and intracoronary bolus doses of adenosine result in the same kind of angina-like chest pains. ${ }^{10}$ Chest pains were not produced when adenosine was given as an infusion into the right atrium at the same dose that provoked pain when given directly into a coronary artery. ${ }^{12}$ Further evidence is provided by the fact that when adenosine was given intravenously to patients with heart transplants the pain threshold was greatly increased. ${ }^{25}$

The difference in sensitivity between the group with ischaemic heart disease and healthy volunteers has not been described before. This could reflect a true difference or it could be the result of the experimental design. Five patients in each of groups A and B were more intensively investigated with invasive monitoring of coronary sinus blood flow and these patients were also premedicated with oxazepam. It is possible that a subjective index such as pain could be influenced by a difference in experimental design such as this. However, this is unlikely because healthy volunteers investigated by coronary sinus catheterisation without premedication reported similar intensities of chest pain to those seen in group $C$ after intravenous bolus doses of adenosine. ${ }^{26}$ Another explanation could be that the patients in groups A and B were all selected because they had chest pain, whereas patients with silent angina may have been recruited from a separate subgroup. We do not know how many of the subjects in group $\mathrm{C}$ might have belonged to this subgroup.

In conclusion, in both patient groups intravenous bolus doses of adenosine provoked chest pain that was no different from their habitual angina. Patients with normal coronary angiograms showed a lower tolerance than patients with coronary stenoses and healthy volunteers. These observations might add to the understanding of patients with angina-like pain but normal coronary angiograms.
This study was supported by grants from the Swedish Heart and Lung Foundation and from Josef and Linnea Carlsson Foundation.

1 Cannon RO, Bonow RO, Bacharach SL, et al. Left ventricular dysfunction in patients with angina pectoris normal epicardial coronary arteries, and abnorma vasodilator reserve. Circulation 1985;71:218-26.

2 Cannon RO, Epstein SE. "Microvascular angina" as a cause of chest pain with angiographically normal coronary arteries. Am J Cardiol 1988;61:1338-43.

3 Greenberg MA, Grose RM, Neuburger N, Silverman R, Strain JE, Cohen MV. Impaired coronary vasodilato responsiveness as a cause of lactate production during pacing-induced ischemia in patients with angina pectoris and normal coronary arteries. J Am Coll Cardiol 1987; 9:743-51.

4 Camici PG, Marraccini P, Lorenzoni, R, et al. Coronary hemodynamics and myocardial metabolism in patients with syndrome X: Response to pacing stress. J Am Coll with syndrome X: Response

5 Opherk D, Zebe H, Weihe E, et al. Reduced coronary dilatory capacity and ultrastructural changes of the dilatory capacity and ultrastructural changes of the
myocardium in patients with angina pectoris but normal myocardium in patients with angina pectoris but

6 Cannon RO, Watson RM, Rosing DR, Epstein SE. Angina caused by reduced vasodilator reserve of the small coronary arteries. J Am Coll Cardiol 1983;1:1359-73.

7 Turiel M, Galassi AR, Glazier JJ, Kaski JC, Maseri A. Pain threshold and tolerance in women with syndrome $\mathrm{X}$ and women with stable angina pectoris. Am J Cardiol 1987; 60:503-7. 8 Sylvén C, Beermann B, Jonzon B, Brandt A. Angina healthy volunteers. $\mathrm{Br}$ Med $J$ 1986;293:227-30.

9 Sylvén C. Angina pectoris. Clinical characteristics, neurophysiological and molecular mechanisms. Pain 1989; 36:145-67.

10 Lagerqvist B, Sylvén C, Beermann B, Helmius G, Waldenström $A$. Intracoronary adenosine causes angina pectoris strom A. Intracoronary adenosine causes angina pectoris like pain-an inquiry into the
Cardiovasc Res 1990;24:609-13.

11 Lagerqvist B, Sylvén C, Hedenström H, Waldenström A Intravenous adenosine but not its first metabolite inosine provokes chest pain in healthy volunteers. $J$ Cardiovas Pharmacol 1990;16:173-6.

12 Crea F, Pupita G, Galassi AR, et al. Role of adenosine in pathogenesis of anginal pain. Circulation 1990;81:164-72.

13 Picano E, Lattanzi F, Masini M, Distante A, L'Abbate A Usefulness of a high-dose dipyridamole-echocardiography test for diagnosis of Syndrome X. Am J Cardio 1987;60:508-12.

14 Lagerqvist B, Bylund H, Götell P, Mannting F, Sandhagen $B$, Waldenström $A$. Coronary artery vaso-regulation and left ventricular function in patients with angina pectorislike pain and normal coronary angiograms. J Int Med 1991;230:55-65.

15 Roos H, Pfleger K. Kinetics of adenosine uptake by erythrocytes, and the influence of dipyridamole. Mol Pharmacol 1972;8:417-25.

16 Ginsburg R, Lamb IH, Bristow MR, Schroeder JS Harrison DC. Application and safety of outpatient ergonovine testing in accurately detecting coronary spasm in novine testing in accurately detecting coronary spasm in
patients with possible variant angina. Am Heart J 1981; patients with

17 Borg G. A category scale with ratio properties for intermodal and interindividual comparisons. In: Geissler H-G, Petzold P, eds. Psychophysical judgement and the progress of perception. Berlin: VEB Deutscher Verlag de Wissenschaften, 1982;25-34

18 Ganz W, Tamura K, Marcus HS, Donoso R, Yoshida S, Swan HJC. Measurement of coronary sinus blood flow by continuous thermodilution in man. Circulation 1971;44: 181-95.

19 Cannon RO, Quyyumi AA, Schenke WH, et al. Abnormal cardiac sensitivity in patients with chest pain and normal coronary arteries. J Am Coll Cardiol 1990;16:1359-66.

20 Berne RM, Cardiac nucleotides in hypoxia: Possible role in regulation of coronary blood flow. Am J Physiol 1963; 204:317-22.

21 Bardenheuer $\mathbf{H}$, Hofling B, Fabry A, Peter K. Increased adenosine production by the heart during acute coronary adenosine production by the heart during acute

22 Okazaki Y, Hirayama A, Sato H, Kitakaze M, Kodama K. Adenosine release during exercise accounts for warm-up phenomenon at 2nd exercise. Circulation 1990;82: III-444.

23 Edlund A, Fredholm BB, Patrinani P, Patrono C, Wennmalm $\AA$, Wennmalm $M$. Release of two vasodilatorsadenosine and prostacyclin-from isolated rabbit hearts during controlled hypoxia. $J$ Physiol 1983;340:487-501.

24 Levy RD, Shapiro LM, Wright C, Mockus L, Fox KM Syndrome $X$ : the haemodynamic significance of ST segment depression. Br Heart J 1986;56:353-7.

25 Lagerqvist B, Sylvén C, Helmius G, Waldenström A. Effects of exogenous adenosine in a patient with transplanted heart. Evidence for adenosine as a messenger in angina pectoris. Ups J Med Sci 1990;95:137-45.

26 Sylvén C, Jonzon B, Edlund A. Angina pectoris-like pain provoked by i.v. bolus of adenosine: relationship to coronary sinus blood flow, heart rate and blood pressure in healthy volunteers. Eur Heart J 1989;10:48-54. 